\title{
Seismic Swarm Activity in and around the Izu Peninsula Preceding the Volcanic Eruption of July 13, 1989
}

\author{
Shozo Matsumura, ${ }^{*}$ Tadashi Ohkubo, and Masajiro Imoto \\ National Research Institute for Earth Science and Disaster Prevention, \\ Tsukuba 305, Japan
}

\begin{abstract}
We have investigated features of the seismic swarm activity preceding the volcanic eruption of July 13, 1989, at the Teisi Knoll located off the east coast of the Izu Peninsula. The whole activity can be divided into two groups: the eastern group around off coast of Ito City and the western group near Ito City. The eastern activity consists of earthquakes primarily related to possible magma intrusions by taking several features into account: burst-like activities with quasi-periodic occurrences, rapid epicentral migrations with short steps, and the coincidence of linear epicentral trends with the tectonic compressional direction. On the other hand, the western activity may have been caused by the largest earthquake occurring on July 9 , and its sequence of aftershocks. Seismic activity comprising both magma-originated earthquakes and tectonic earthquakes is recognized as one of several typical seismicity patterns observed around the Izu area.
\end{abstract}

\section{Introduction}

For more than ten years, extensive earthquake swarms have been annually recorded around the Izu Peninsula. The National Research Institute for Earth Science and Disaster Prevention (NIED) has continuously operated a high quality, systematic, microearthquake observation network covering this area since 1979 (Hamada et al., 1985). Based on the data obtained by this network, several researchers have investigated the swarm activities in the region, and have tried to interpret occurrence mechanisms. Ishida (1984) made a detailed analysis of the 1980 earthquake swarm near the Izu Peninsula, and revealed differences in seismicity patterns between swarm activity and associated main rupture with aftershocks by examining their spatial-temporal variations, spectra, and focal mechanisms. Review works focusing on swarm activities were presented by Ishida (1987) and Hori (1989), who examined every swarm for the last decade, and summarized the individual and common features of their occurrence patterns.

The latest seismic swarm around the Izu Peninsula began at the end of June, 1989, and continued for more than one month. This event was unique and important in the history of earthquake swarms around this area. Even though the swarm has been regarded as simply recurring activity continued from the previous sequences, there

Received August 27, 1990; Accepted November 14, 1990

* To whom correspondence should be addressed. 
appeared several unusual phenomena: the level of seismicity developed to be the highest ever observed (JMA, 1990), the focal region stepped into the inland area of Ito City, and its focal depth was the shallowest ever observed, and especially, it was associated with clearly observed volcanic activities, i.e. microseisms, low frequency earthquakes, and submarine eruption. Though the relationship between earthquake swarms and magma behavior around the Izu area has previously been noted (for example, Nasu, 1935; Kuno, 1954; Mogi, 1985; Mizoue, 1988), this was the first event which provided direct evidence substantiating these hypotheses.

In this paper, we focus on this event by introducing results of our microearthquake observations along with discussions and interpretations of the phenomena.

\section{Observation and Data Processing}

The observational network system of NIED functioned well through the entire active period. From July 3, 16:25 to July 17, 13:24 (excepting one short period on July 5, 08:06-09:37), 74 volumes of 2,400 foot computer tapes were recorded and archived. Routine data processing, including determination of hypocenters and focal mechanisms, is still currently on going using the APE system (the Analyzing System for Precursors

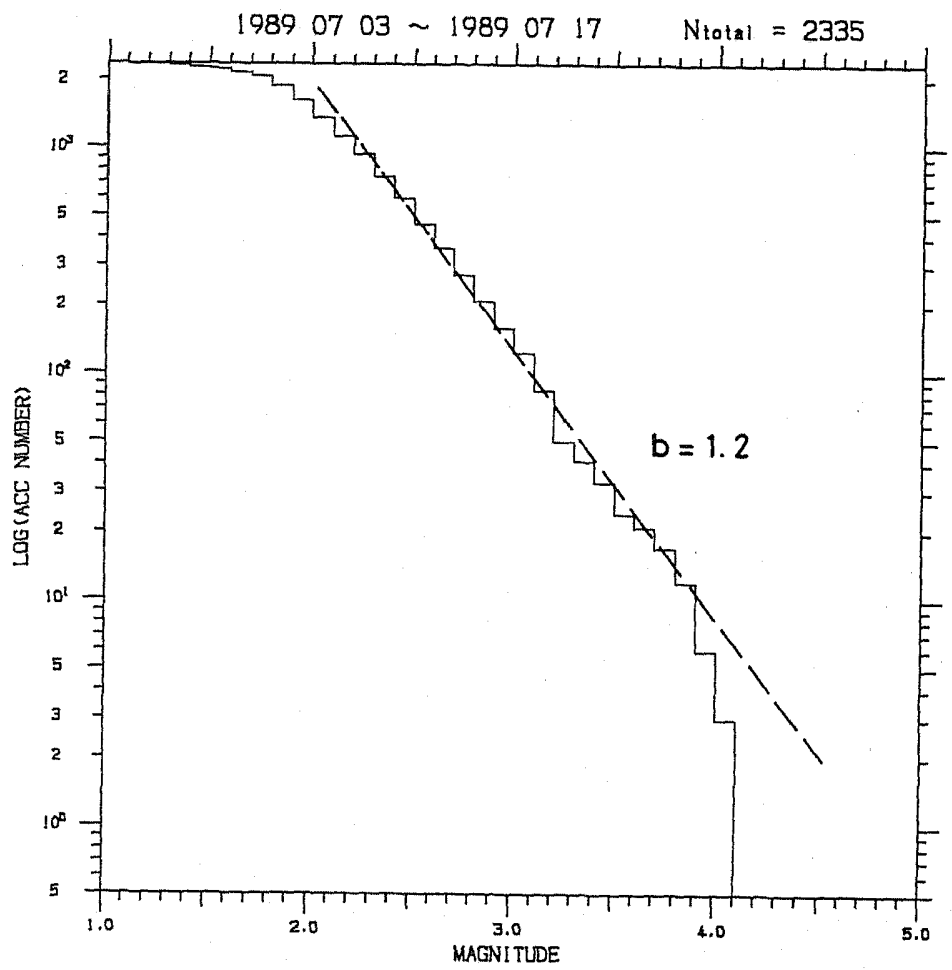

Fig. 1. Magnitude-accumulated frequency diagram for swarms in July, 1989. Earthquakes greater than magnitude 2.2 or 2.3 could be uniformly detected. The $b$-value was estimated at 1.2 . 


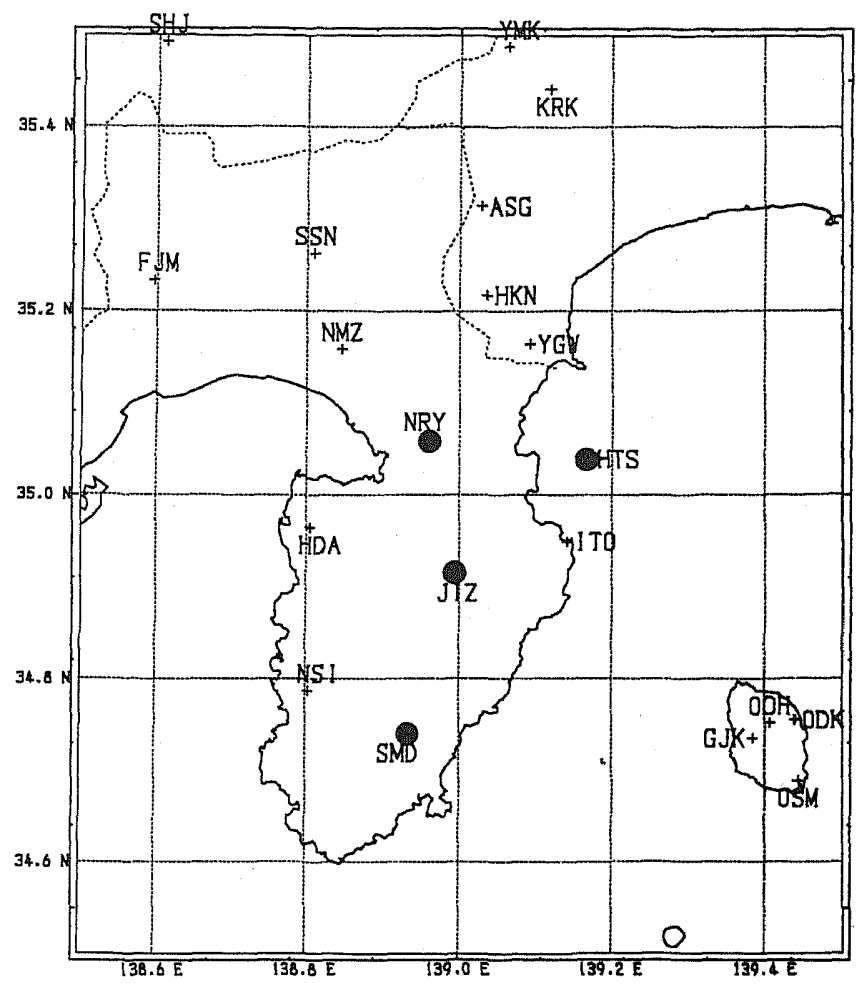

Fig. 2. Station distribution of the National Research Institute for Earth Science and Disaster Prevention around the Izu area. Four stations marked with solid circles were selected for detailed redetermination of hypocenters.

of Earthquakes; Matsumura et al., 1988). Besides routine processing, an additional procedure developed by Imoto (1990), which entails quick results on earthquake swarm events, was applied to the data. Utilizing this procedure, a total of 2,335 earthquakes were extracted and processed from the saved data. Figure 1 shows a magnitudeaccumulated frequency diagram resulting from this procedure. Fitting a straight line to the curve provides a $b$-value estimate of approximately 1.2 with the minimum magnitude for uniform detection about 2.2-2.3.

Initially, hypocenter determination was carried out by picking arrivals of P- and S-phases for 29 stations, some of which were fairly distant from the focal region. In order to be sure of relative uniformity, we tried to redetermine hypocenters using only nearby stations. Four stations, HTS, JIZ, NRY, SMD, surrounding the focal region were selected for this purpose (Fig. 2). The closest station, ITO, was not used because telemetry from this site started only after the commencement of activity. Also those stations in the Oshima Island were not used because of their relatively low detection capabilities in spite of their advantageous locations for hypocenter determination.

Although only four stations are not sufficient for accurate hypocenter determination, a restricted distance offset is required for determination of detailed structures associated 


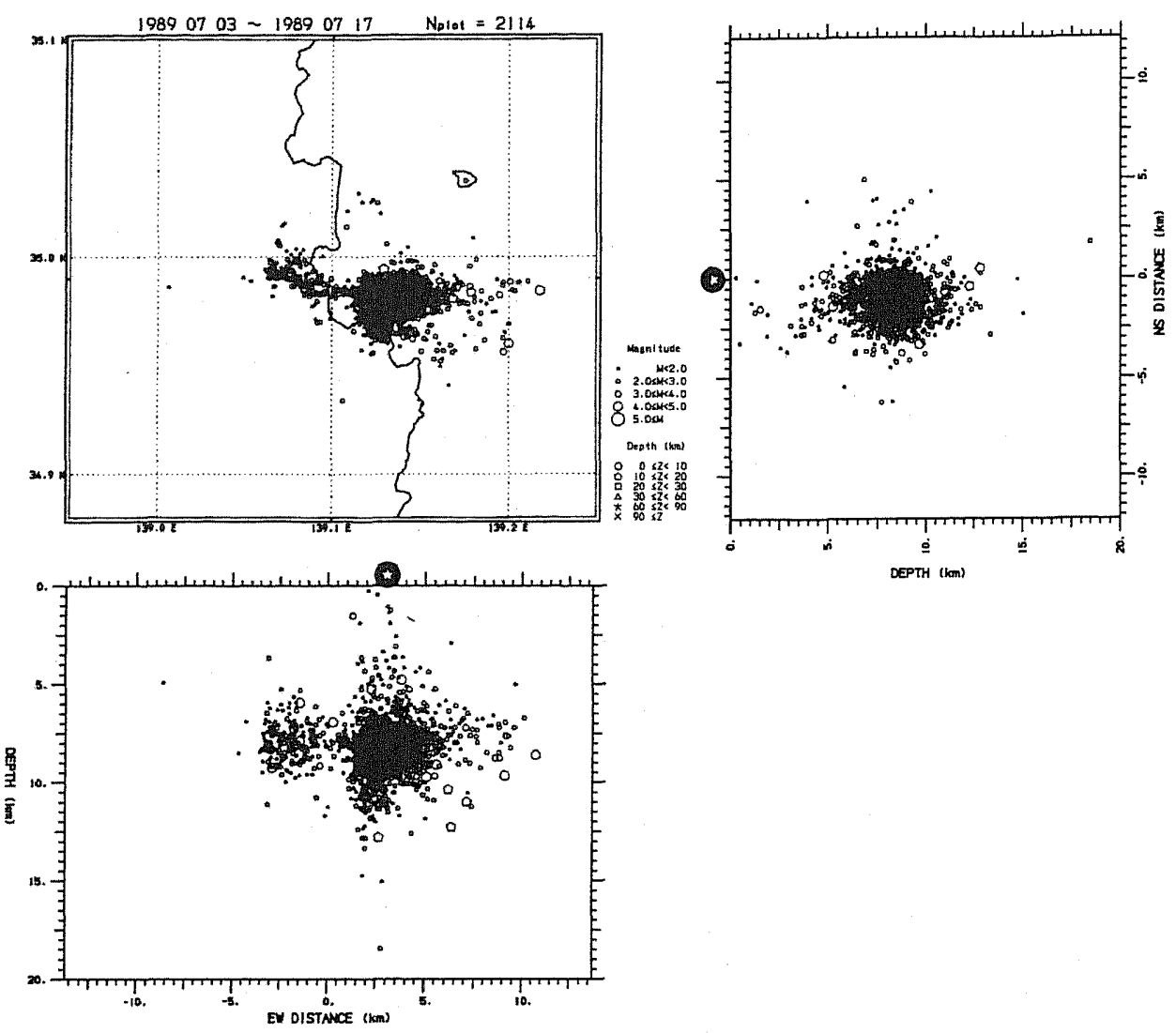

Fig. 3. Epicentral distribution and cross sections for swarms in July, 1989. Stars indicate the eruption location.

with seismicity patterns. In this way, we can avoid serious problems caused by effects of strong inhomogeneity of local velocity structure around the volcanic region and non-uniform detection of seismic signals at distant stations. For detailed hypocenter redeterminations, a horizontally stratified velocity model was employed (Ukawa et al., 1984), and station corrections were incorporated to remove local structure effects. Station corrections were determined by simply averaging residuals of arrival times (O-C) calculated in the initial hypocenter determination. A final total of 2,114 hypocenters were thus redetermined.

\section{General Aspects of Seismic Activity}

The epicentral map and their cross sections are represented in Fig. 3. The mean focal depth of our results, ranging from 6 to $10 \mathrm{~km}$, is comparatively deeper than those reported by other organizations: 0-6 km (JMA, 1990), 4-8 km (ERI and MRI, 1990), and $1-6 \mathrm{~km}$ (Tohoku University, 1990). This may be due to the unrealistic initial velocity 


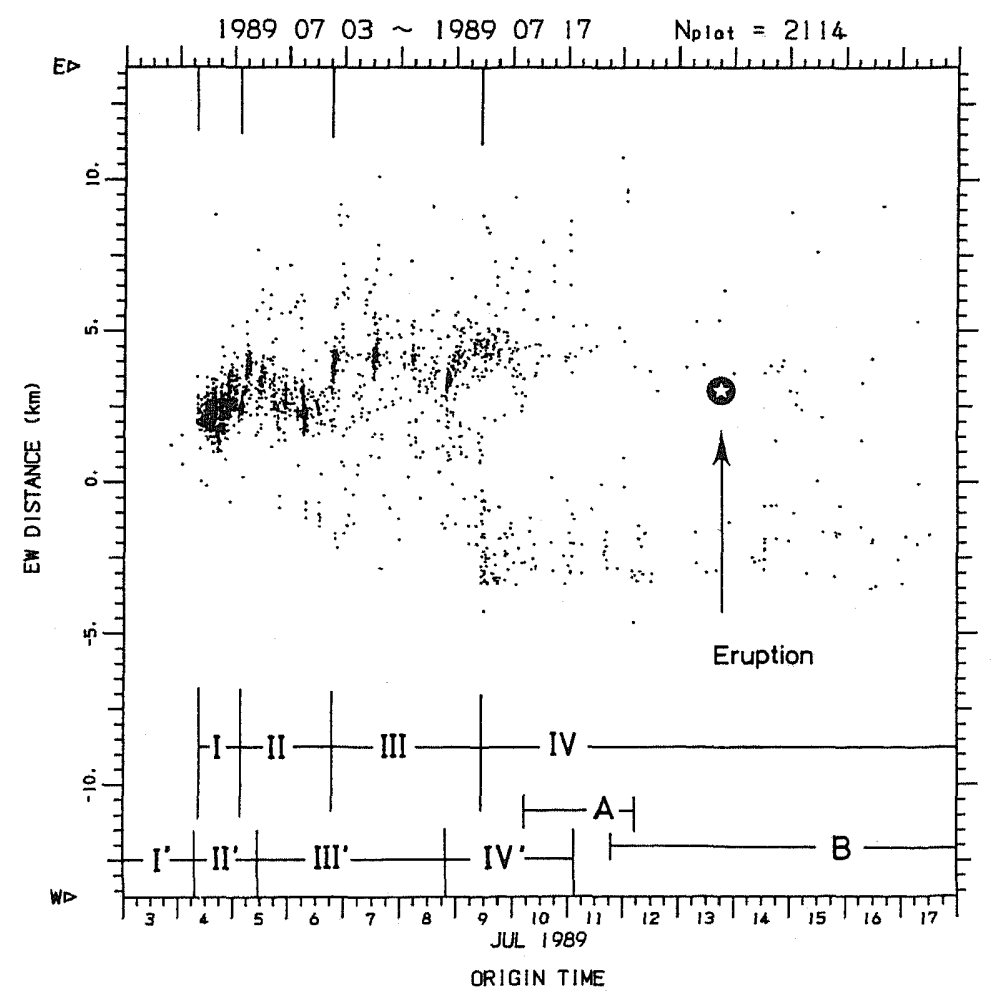

Fig. 4. Space-time distribution diagram projected on an East-West axis. The whole period is divided into four stages (I, II, III, IV) by distinguishing patterns of burst-like activity. Another classification of the period with stages $\mathbf{I}^{\prime}$ to $\mathrm{IV}^{\prime}$ was introduced by Okada and Yamamoto (1991) which explains the crustal deformation data. ' $A$ ' is a period when characteristic low frequency earthquakes were observed (Obara and Fukuyama, 1990). ' $B$ ' is a period when microseisms were observed (JMA, 1990).

models adopted. However, while absolute errors in the hypocenter locations may be large, relative locations are considered to be worthy of some detailed analysis. The seismically active region can be divided into eastern and western groups, separated at $139.1^{\circ} \mathrm{E}$ longitude. While seismicity in the east occupied almost the same position as the 1985 activities (S8 and S9 in Ishida (1987), S7 and S8 in Hori (1989)), activity in the west was relatively new. In the cross-sectional views of Fig.3, we notice an interesting feature in the eastern group, a vertical alignment rising from the center of the cluster. The location of this vertical distribution appears to coincide with the surface eruption, Teisi Knoll marked by a star, indicating that magma has intruded through it.

A space-time distribution diagram projected along the east-west direction is illustrated in Fig. 4. The entire period was divided into four stages according to seismic occurrence patterns: I, (08 h, July 4-03 h, July 5); II,(03 h, July 5-20 h, July 6); III, (20 h, July 6-11 h, July 9); IV, (11 h, July 9-July 17). From stages I to III, burst-like swarms 


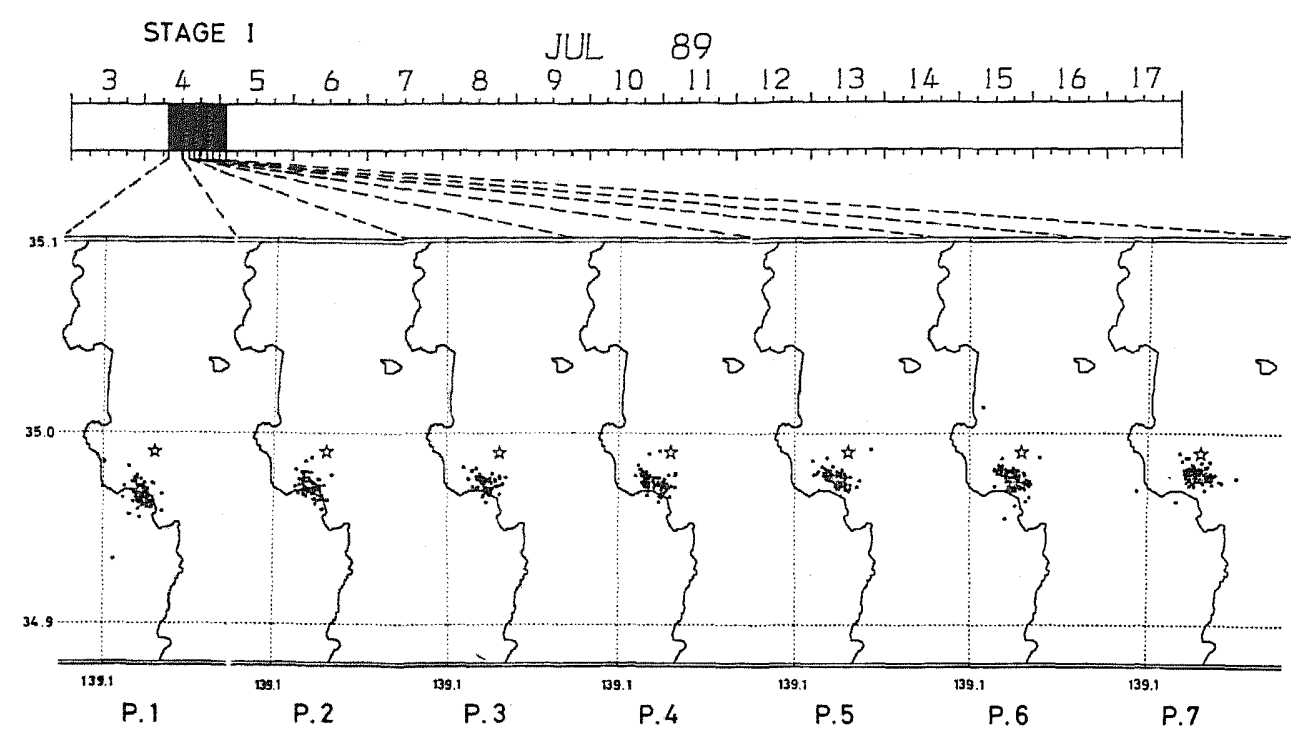

(a)

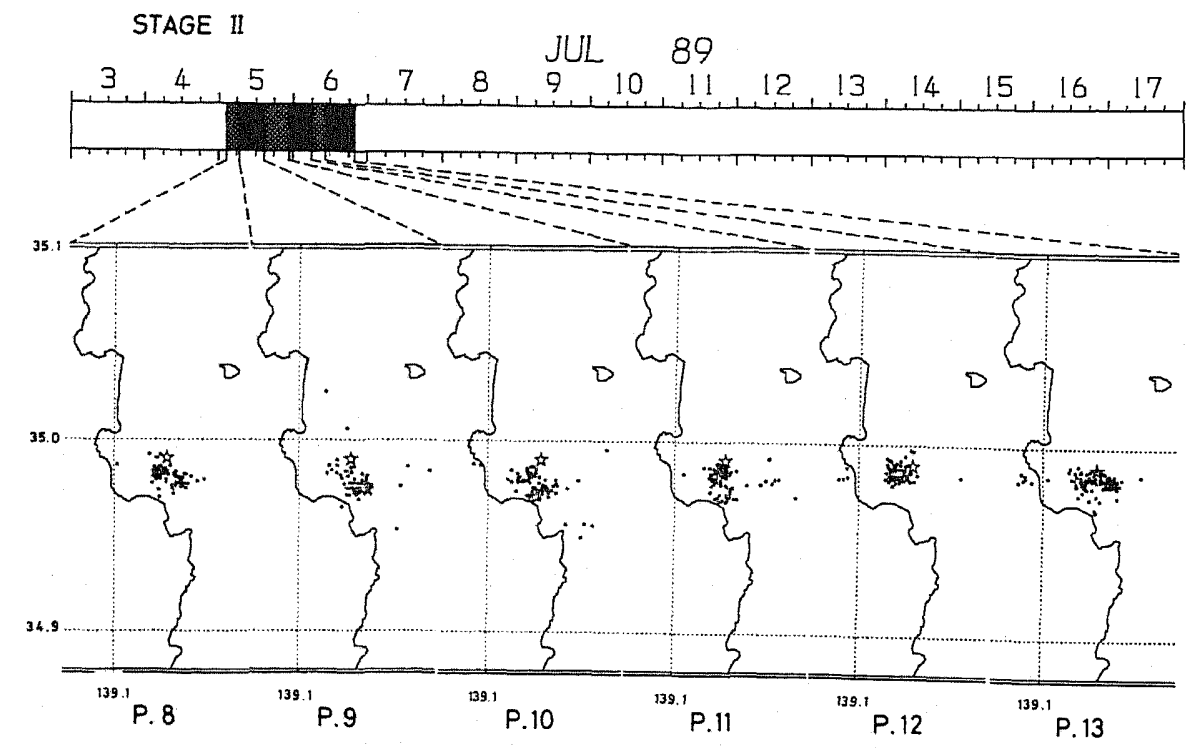

(b)

Fig. 5. Variation of epicentral distribution. (a) to (d) correspond to the stages from I to IV, respectively. Each part includes about one hundred data points, the actual time duration of which is indicated on the top with a black-and-grey striped band. The star indicates the place of eruption. 


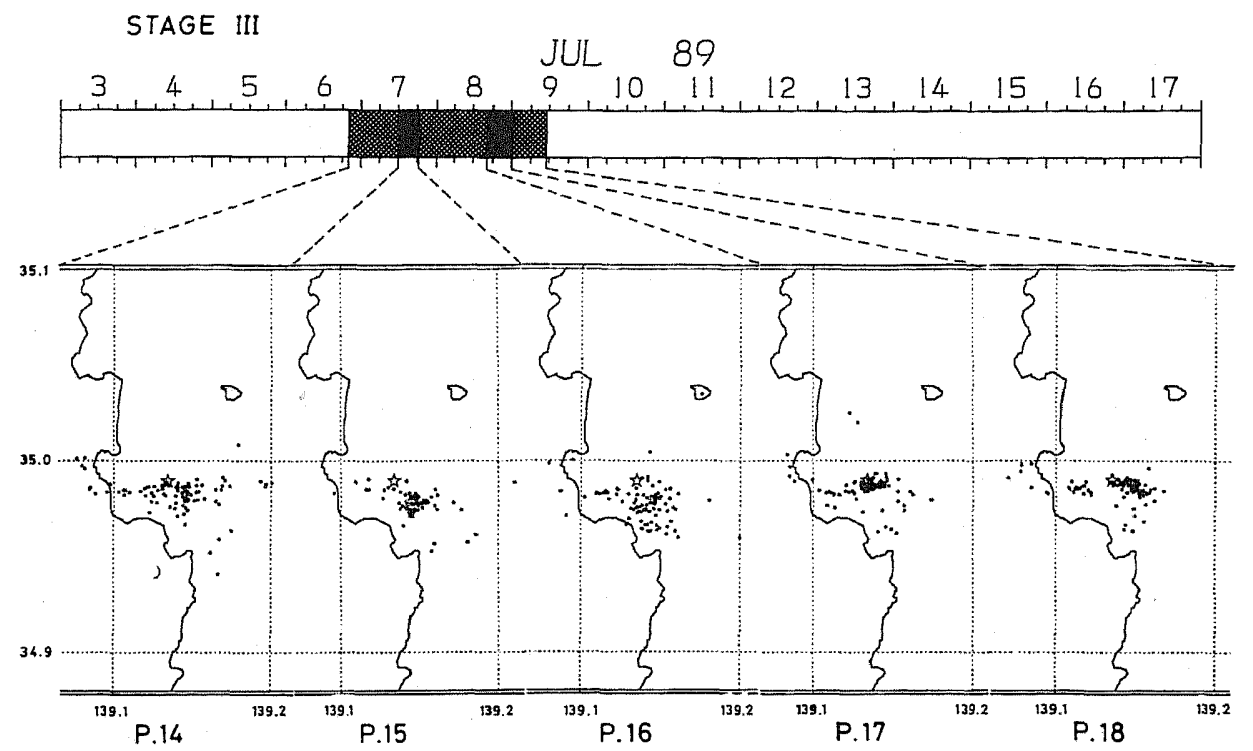

Fig. 5(c)

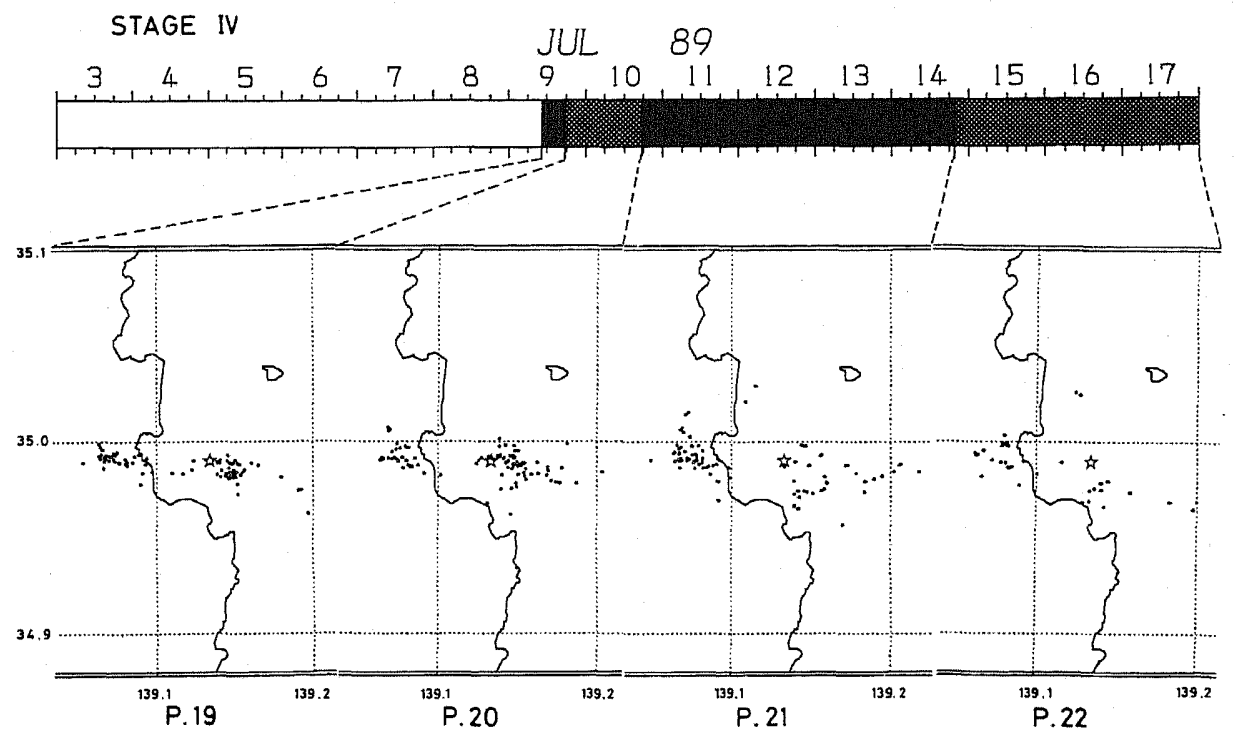

Fig. 5(d)

with quasi-periodic occurrences are observed on the eastern activity, the mean time interval of which is about $3 \mathrm{~h}$ for stage I, $6 \mathrm{~h}$ for stage II, and $16 \mathrm{~h}$ for stage III. Within the eastern activity, the most active seismic zone migrated from west to east in stage I, returned back west in stage II, and stayed mostly to the easternmost area for stage III. On the other hand, the seismicity of the western group was comparatively 
low from I to III, excluding some short periods around $07 \mathrm{~h}, 13 \mathrm{~h}$, and $20 \mathrm{~h}$ on July 6 , which may have been triggered by concurrent bursts along the east. At 11:09, on July 9, in stage IV, the largest earthquake (M 5.5) in the major swarm took place, and a possible fault crossed through the eastern and western groups. Immediately after this large event, seismic activity split clearly east- and westward with intermediate zone becoming very quiet. Eventually, both activities gradually decayed with time.

\section{Migration of Hypocenters}

The entire seismic sequence exhibits a fairly complex pattern as shown in Fig.4. It is interesting to divide the whole activity temporally into many small parts, and observe them chronologically as in an animation. Here, a total of 2,114 earthquakes were divided into 22 parts (P.1-P.22), each of which contained about 100 earthquakes. The results are shown in Fig. 5 (a)-(d), where we note that the time duration of each part varies with the actual time width of each part indicated on the black-and-grey striped band above. The period including P.1-P.7 corresponds to stage I defined in the previous section, P.8-P.13 to stage II, P.14-P.18 to stage III, and P.19-P.22 to stage IV.

On the morning of July 4, an extensive swarm developed near Shiofuki point (P.1). It migrated northwestward, along the trend of the cluster (P.2), and then, shifted to the east gradually (P.3-P.7), approaching the submarine eruption point. From P.8, at the beginning of stage II, the activity tended to separate into two blocks (NW and SE blocks). In the first half of stage II, the SE block was more active than the NW block (P.9-P.10), but later, this situation reversed (P.11-P.13). Through P.14 to P.18 (stage III), activity expanded along the east-west direction, and extended into the Izu Peninsula. This trend portended the forthcoming fault breakage during the largest earthquake (M 5.5) at 11:09 on July 9. From P.15 to P.16, the south-eastern region again became active, but was slightly separated from the source region of SE block in stage II. Each swarm activity seems to have created new clusters, filling up previously quiescent areas in succession. While we must qualify our results by noting that absolute hypocenter determinations are not available, we feel confident in our solution because the pattern of epicentral migrations, starting at some distance from the eruption point, converged there just prior to the eruption.

The M5.5 earthquake took place at the end of P.18. After this event, activity was split geographically into two areas, both of which were dispersed and decayed gradually (P.19-P.22). In the final stage (P.19-P.22), we faintly recognize the same features reported by Tohoku University (1990), where they used a dense network of new stations, getting precise locations of several concentrated clusters of aftershock activity (after July 18).

\section{Focal Mechanism Solutions}

Focal mechanism solutions were determined for some comparatively large earthquakes $(M>3.0)$, with more than 20 first motion polarization readings. A distribution of horizontally-projected compressional axes for 76 calculated focal mechanisms is displayed in Fig. 6(a), while (b) and (c) indicate space-time diagrams of the compressional and the tensional axes, respectively. The averaged compressional 


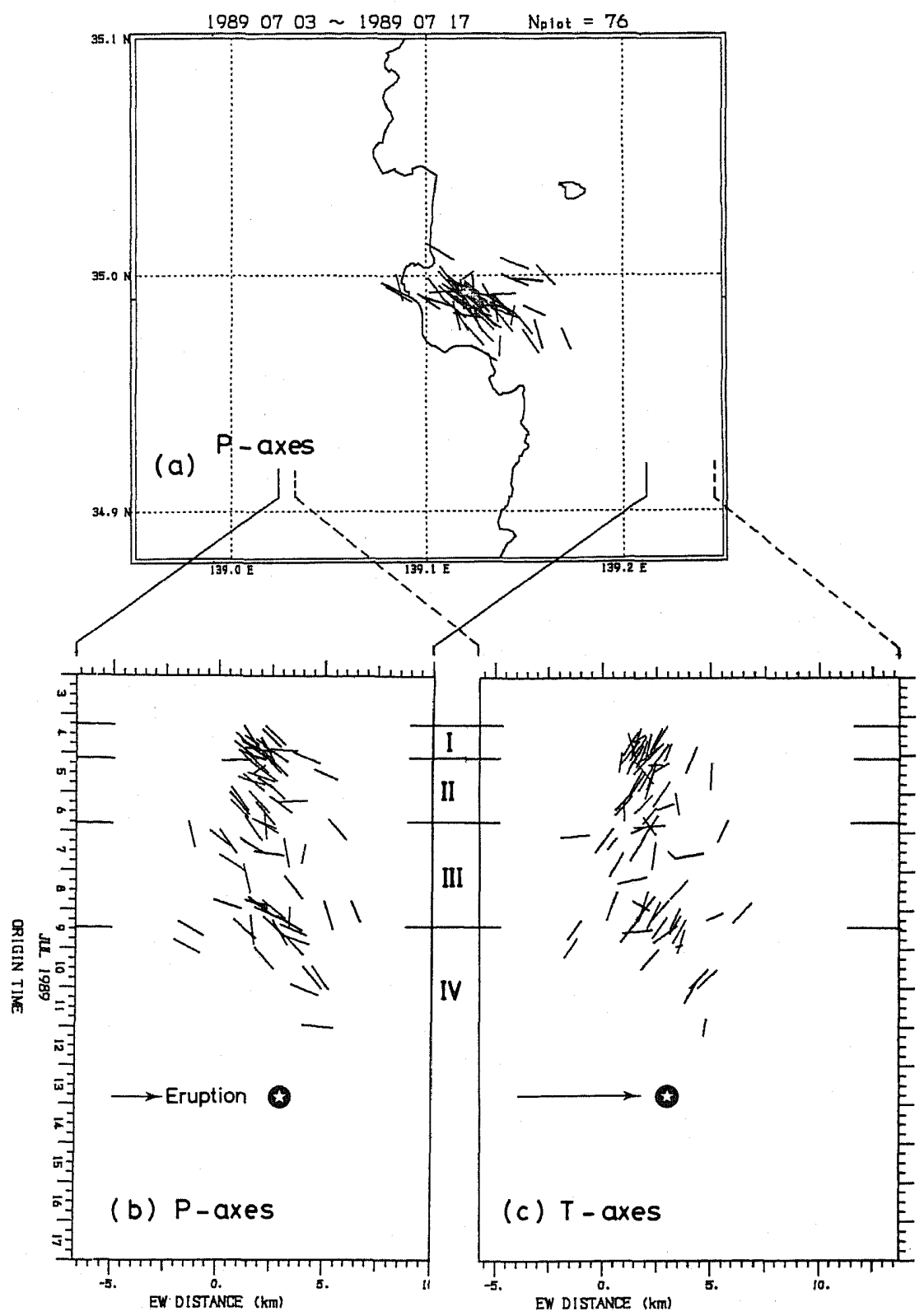

Fig. 6. Results of focal mechanism analysis. (a) Distribution pattern of compressional stress axes projected on a horizontal plane. (b) Space-time distribution diagram of compressional stress axes. (c) Space-time distribution diagram of tensional stress axes.

Vol. 39, No. 1, 1991 


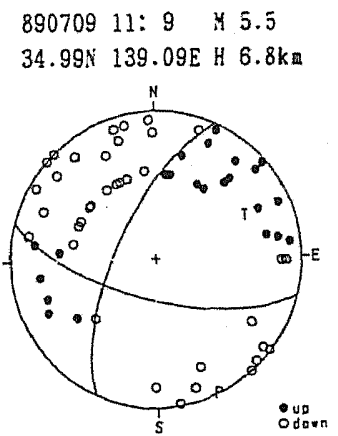

(a)

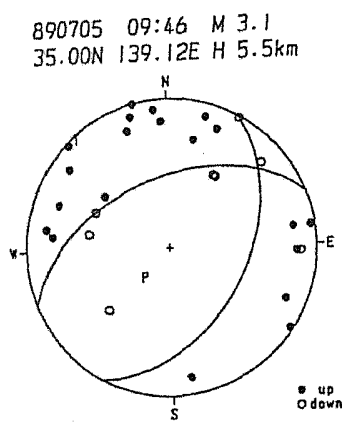

(b)

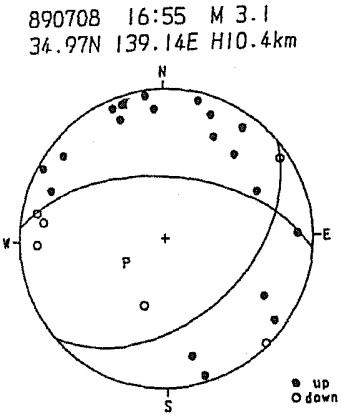

(c)

Fig. 7. Examples of focal mechanism solutions projected on a lower hemisphere.

(a) The solution for the large $M 5.5$ earthquake. (b) and (c) are examples of exceptional solutions.

direction is nearly NW-SE, and the corresponding tensional direction is NE-SW. In particular, we note that faults of strike-slip type are generally dominant. This tendency is in agreement with the ambient stress pattern and with results obtained from previous studies (Hori, 1989), where more than $80 \%$ of the solutions were classified as strike-slip type events with compressional axes along the NW-SE direction. The focal mechanism solution for the largest earthquake (M5.5) is typical and is presented in Fig. 7(a). In contrast, Fig. 7(b) and (c) shows results for two unusual solutions indicating normal type faulting with tensional axes along NW-SE direction, a stress pattern conflicting with the ambient conditions. In an independent analysis, 65 focal mechanism solutions for the sequences after July 16, indicated a mixture of reverse and normal type fault mechanisms with a dominant distribution of strike-slip type mechanisms (Tohoku University, 1990). Mixtures of various types of mechanisms, particularly with normal faults associated with magma intrusion often appear in volcanic regions (see for example, Yamaoka et al., 1988). However, mechanisms conflicting with ambient stress conditions have never been observed or reported. Although we cannot provide an extensive explanation for this phenomenon, it may represent the particular tectonic conditions induced by the volcanic activity around this area.

A close examination of Fig. 6(b) and (c), indicates that some irregular solutions stray from the average trend. During stages I and II, some solutions with nearly EW compressional axes appear at several positions on the average pattern of NW-SE axes, while solutions with nearly NS compressional axes frequently appear in stage III. We offer two possible sources for such observed irregularities. One is to introduce a local irregularity of redistributed stress pattern, possibly induced by the preceding activity. The other is to assume some mechanically weak pre-existing fractures. In either case or in both cases taken together, we suppose that a slight but significant change of dominant stress pattern occurred between stages II and III. 


\section{Discussion}

For the period July $3-17$, the most striking natural event in this region was the volcanic eruption at Teisi Knoll, which occurred at 18:33 on July 13 (JMA, 1990). Preceding this eruption, two kinds of characteristic seismic signals, implying volcanic activity, were observed. One was the characteristic low frequency earthquakes observed mainly from $05 \mathrm{~h}$ on July 10 to $06 \mathrm{~h}$ on July 12 (Obara and Fukuyama, 1990), and the other was extensive microseisms observed throughout the period from $20 \mathrm{~h}$ on July 11 to $13 \mathrm{~h}$ on July 21 . The appearance of microseisms and low frequency earthquakes, in conjunction with the eruption, are presumed to be phenomena caused by magma residing at very shallow depths. As shown in Fig. 4, the beginnings of these volcanic phenomena nearly correspond to the termination of the active seismic period. This implies that when these phenomena, directly related to the volcanic activity, were observed, magma had already penetrated through the seismogenic zone.

Yamamoto et al. (1991) noted a strong correlation between the swarm activity and the progression of crustal deformation observed at a tiltmeter installed at ITO. Okada and Yamamoto (1991) noted that magma intrusion had progressed during the period of active swarms, and they proposed a dislocation model explaining crustal deformation of various kinds, including crustal tilt, crustal strain, distance and level changes and others. They suggested a model with two opening fractures along the seismically active zones, one of which is related to the seismic swarm of May, 1989, and the other related to the July 1989 swarm. The latter swarm, investigated here, was modeled as a magma intrusion beginning on July 1 , and terminating on July 11 . It is probable that the magma intrusion would generate kinetic or thermal stress on the surrounding region, and trigger seismic events, which were ready to occur after the accumulation of tectonic stress. According to their model, the main intrusion progressed over four stages, I' (July 1-08 h, July 4), II' (08 h, July 4-11 h, July 5), III' (11 h, July 5-20 h, July 8), and $\mathrm{IV}^{\prime}(20 \mathrm{~h}$, July $8-3 \mathrm{~h}$, July 11$)$. This progressing by stages approximately corresponds to our own classification by stages for the seismic activity, where II $^{\prime}$ corresponds to I, III' to II and III, and IV' to IV. It should be noted that during the period from stages I to III, quasi-periodic bursts occurred, and their average time intervals increased during the progress of the stage. These phenomena are reminiscent of "geysers," and we suggest the following speculation: the periodic activity is related to characteristic oscillations generated by an interaction between liquid and gas phases. The increase of the time interval might be attributed to the decrease of pressure or the volume increase of co-oscillating space derived by the progress of opening of the fracture.

Okada and Yamamoto (1991) arrived at their model by taking into account epicentral aspects of the active period, and suggested an open-type fault striking $\mathrm{N} 125^{\circ} \mathrm{E}$, approximately parallel to the ambient compressional direction assumed from motion of the Philippine Sea plate $\left(\mathrm{N} 126^{\circ} \mathrm{E}\right.$ by Seno, 1977) as shown in Fig. 8 with arrows. The coincidence of the directions of the ambient compressional axis and the linear trend of the seismically active zone can be explained by the opening of microcracks generated by magma-originated liquid or gas intrusion (Nakamura and Ui, 1975). Furthermore, a rapid change of seismically active zones over the eastern portion suggests a mechanism

Vol. 39, No. 1, 1991 


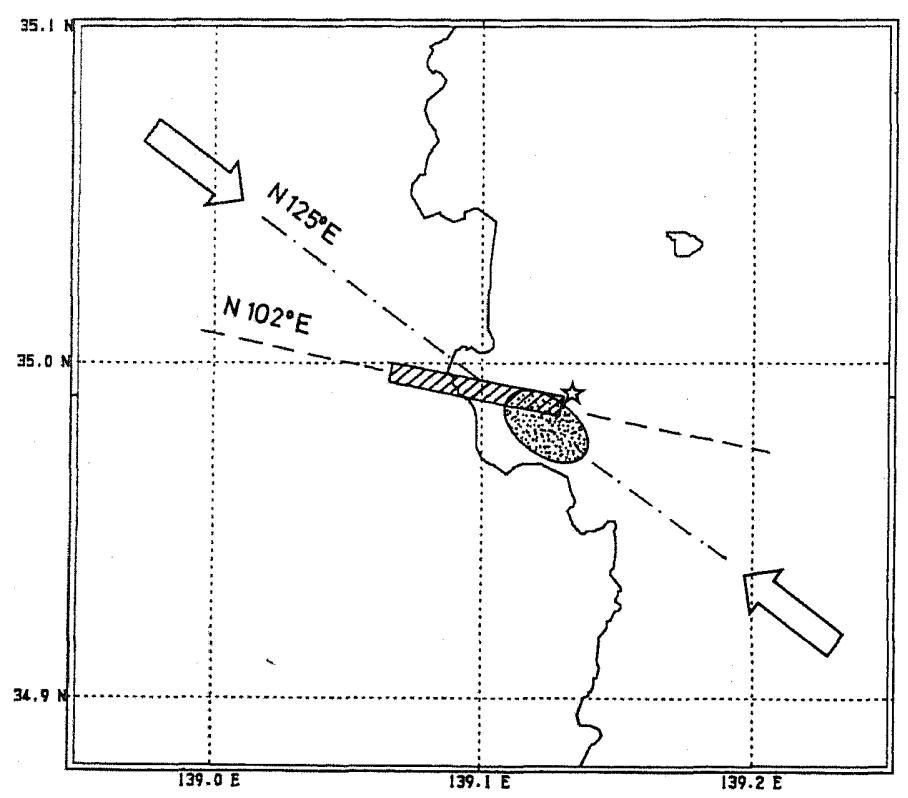

Fig. 8. Schematic model to explain the swarm activities in July, 1989 (modified from Okada and Yamamoto (1991)). The hatched rectangle shows a fault model for the largest earthquake of $M 5.5$. The shadowed ellipse shows an active seismic area preceding the largest earthquake, and the broken line denotes their trend. The star mark indicates the place of the eruption. The open arrows indicate the moving direction of the Philippine Sea plate (after Seno, 1977).

caused by the presence of fluids. It appears that all the phenomena analyzed and interpretations previously introduced support the assumption of magmatic intrusion in the eastern half of the swarm activity.

In contrast to the eastern side, the western activity did not establish any special features indicating magma intrusion. It can be concluded that the western activity was mainly associated with aftershock sequences of the large $M 5.5$ earthquake, and was not volcanic but of tectonic origin. The large $M 5.5$ earthquake was modeled using its focal mechanism solution (Fig. 7(a)) and aftershock distributions as shown with a hatched shape in Fig. 8, where the fault plane was striking $\mathrm{N} 102^{\circ} \mathrm{E}$, and dipping toward south with an angle of $79^{\circ}$ (Okada and Yamamoto, 1991). The total seismicity pattern shown in Fig. 8 is quite similar to that of the East-off Izu Peninsula Earthquake (M6.7) of 1980, analyzed by Ishida (1984). In 1980, prior to the main shock, an earthquake swarm formed a linear trend along the ambient compressional direction. Later, the main shock fault initiated from a point within the active swarm zone and ruptured obliquely at about $45^{\circ}$ to the average compressional direction. The present case quite resembles this situation, except that the strike of the main shock fault is perpendicular to that of the 1980 event, i.e., it assumes a conjugate direction. According to Nakamura (1987), mechanical weaknesses in volcanoes often generate foreshocks or 
earthquake swarms, and increasing stress causes sudden ruptures forming main faults which trend with the ambient tectonic conditions. Thus, the seismic activity studied in this paper can be regarded as typical of volcanic regions.

We are grateful to Dr. Yoshimitsu Okada for many suggestions and encouragement, and to Dr. Jonathan Lees for useful comments. We also thank the other members of the National Research Institute for Earth Science and Disaster Prevention, and the operators who performed the laborious work of data processing.

\section{REFERENCES}

Earthquake Research Institute, the University of Tokyo and Meteorological Research Institute, Japan Meteorological Agency, Seismic activities in the Izu Peninsula and its vicinity (May-October, 1989), Rep. Coord. Comm. Earthq. Predict., 43, 157-174, 1990 (in Japanese).

Hamada, K., M. Ohtake, Y. Okada, S. Matsumura, and H. Sato, A high quality digital network for microearthquake and ground tilt observations in the Kanto-Tokai area, Japan, Earthq. Predict. Res., 3, 447-469, 1985.

Hori, S., Recent swarm activity around the Izu Peninsula, Rep. Natl. Res. Cent. Disas. Prev., 43, 127-167, 1989 (in Japanese).

Imoto, M., Semi-automatic data processing for an earthquake swarm, Rep. Natl. Res. Cent. Disas. Prev., 45, 41-51, 1990 (in Japanese).

Ishida, M., Spatial-temporal variation of seismicity and spectrum of the 1980 earthquake swarm near the Izu Peninsula, Japan, Bull. Seismol. Soc. Am., 74, 199-221, 1984.

Ishida, M., Recent seismic activity in and around the Izu Peninsula, Proceedings of Earthquake Prediction Research Symposium, 51-60, 1987 (in Japanese).

Japan Meteorological Agency, Earthquake Prediction Information Division, Seismic activity in and around the Izu Peninsula (May-October, 1989), Rep. Coord. Comm. Earthq. Predict., 43, 140-156, 1990 (in Japanese).

Kuno, H., Geology and petrology of Omuro-yama volcano group, North Izu, J. Fac. Sci., Univ. Tokyo, Sec. 2, 9, 241-265, 1954.

Matsumura, S., Y. Okada, M. Imoto, S. Shimada, S. Hori, T. Ohkubo, M. Ohtake, and K. Hamada, The functions and constitutions of the Analyzing System for Precursors of Earthquakes (APE), Rep. Natl. Res. Cent. Disas. Prev., 41, 35-44, 1988 (in Japanese).

Mizoue, M., A seismic swarm activity off east of the Izu Peninsula and magma intrusion, Proceedings of 1988 Fall Meeting of Seismological Society, 50, 1988 (in Japanese).

Mogi, K., Earthquake Prediction, Academic Press, London, pp. 185-242, 1985.

Nakamura, K., Volcanoes as mechanically weak spots in the crust, with special reference to the 1986 eruption of Izu-Oshima Volcano, Proceedings of Earthquake Prediction Research Symposium, 237-241, 1987 (in Japanese).

Nakamura, K. and T. Ui, Possible role of pore pressure in 1974 volcanic earthquakes of Chokai Volcano, KAZAN II, 20, 103-104, 1975 (in Japanese).

Nasu, N., Recent seismic activities in the Idu Peninsula (Part 2), Bull. Earthq. Res. Inst., Univ. Tokyo, 13, 400-415, 1935.

Obara, K. and E. Fukuyama, Low frequency earthquakes associated with the swarm off Ito, Rep. Coord. Comm. Earthq. Predict., 43, 209-213, 1990 (in Japanese).

Vol. 39, No. 1, 1991 
Okada, Y. and E. Yamamoto, A model for the 1989 seismo-volcanic activity off Ito, central Japan, derived from crustal movement data, J. Phys. Earth, 39, 177-195, 1991.

Seno, T., The instantaneous rotation vector of the Philippine Sea plate relative to the Eurasian plate, Tectonophysics, 42, 209-226, 1977.

Tohoku University, Faculty of Science, Earthquake swarm off the east coast of the Izu Peninsula caused by volcanic eruption of the Teishi Seamount, Rep. Coord. Comm. Earthq. Predict., 43, 182-190, 1990 (in Japanese).

Ukawa, M., M. Ishida, S. Matsumura, and K. Kasahara, Hypocenter determination method of the Kanto-Tokai observational network for microearthquakes, Res. Notes Natl. Res. Cent. Disas. Prev., 53, 1-88, 1984 (in Japanese).

Yamamoto, E., Y. Okada, and T. Ohkubo, Ground tilt changes preceding the 1989 submarine eruption off Ito, Izu Peninsula, J. Phys. Earth, 39, 165-175, 1991.

Yamaoka, K., H. Watanabe, and S. Sakashita, Seismicity during the 1986 eruption of Izu-Oshima Volcano, KAZAN II, 33 (special issue), 91-101, 1988 (in Japanese). 